\title{
Identification of resistant carboxylesterase alleles in Culex pipiens complex via PCR-RFLP
}

\author{
Hanying Zhang ${ }^{1}$, Fengxia Meng ${ }^{2}$, Chuanling Qiao ${ }^{1}$ and Feng Cui ${ }^{1 *}$
}

\begin{abstract}
Background: Carboxylesterase overproduction is a frequently observed resistance mechanism of insects to organophosphate insecticides. As a major transmitter of human diseases, mosquitoes in the Culex pipiens complex have evolved 13 carboxylesterase alleles (Ester) that confer organophosphate resistance. Six alleles, Ester ${ }^{B 1}$, Ester ${ }^{2}$,

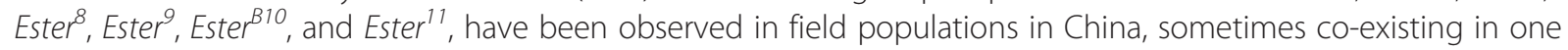
population. To differentiate the carboxylesterase alleles found in these field populations, PCR-RFLP was designed for use in resistance monitoring.

Results: Based on the DNA sequences of resistant and nonresistant carboxylesterase alleles, Ester $B$ alleles were first amplified with PCR-specific primers and then digested with the restriction enzyme Dral. In this step, Ester ${ }^{2}$ and Ester $^{17}$ were differentiated from the other Ester alleles. When the other Ester B alleles were digested with the restriction enzyme Xbal, Ester ${ }^{B 1}$ and the susceptible C. p. pallens Ester were screened out. Ester ${ }^{8}$ and Ester ${ }^{9}$ were differentiated from $E_{s t e}{ }^{B 10}$ and the susceptible C. p. quinquefasciatus esterase allele, respectively, by amplifying and digesting the Ester $A$ alleles with the restriction enzyme ApaLI. The effectiveness of the custom-designed PCR-RFLP was verified in two field mosquito populations.
\end{abstract}

Conclusions: A PCR-RFLP based approach was developed to differentiate carboxylesterase alleles in Culex pipiens complex mosquitoes. These processes may be useful in monitoring the evolutionary dynamics of known carboxylesterase alleles as well as in the identification of new alleles in field populations.

Keywords: Carboxylesterase, Insecticide resistance, Genotype differentiation, Resistance monitor

\section{Background}

Insecticides are vital to agricultural production and public health, particularly in countries with huge human populations, such as China. In China, large quantities of chemical insecticides have been used to control mosquitoes since the mid-1950s. Consequently, resistance has developed in vector mosquitoes, which makes their control increasingly difficult [1]. Mosquitoes in the Culex pipiens complex (Diptera: Culicidae) are common in temperate and tropical countries. These insects have been subjected to insecticide control in many places around the world [2]. Four subspecies comprise the complex: C. p. quinquefasciatus, C. p. pallens, C. p. pipiens, and C. p. molestus. C. p. quinquefasciatus

\footnotetext{
* Correspondence: cuif@ioz.ac.cn

${ }^{1}$ State Key Laboratory of Integrated Management of Pest Insects and

Rodents, Institute of Zoology, Chinese Academy of Sciences, Beijing 100101, China

Full list of author information is available at the end of the article
}

and C. p. pallens are prevalent in South China and North China, respectively [3].

Global surveys of insecticide resistance have indicated that one of the major mechanisms of resistance is the increased detoxification in resistant individuals [4]. Three primary detoxifying enzymes involved in insecticide resistance are carboxylesterase (or esterases), glutathione$\mathrm{S}$-transferases, and $\mathrm{P} 450$ monooxygenases, which are qualitatively or quantitatively changed to confer resistance [5]. Esterase overproduction is a common resistance mechanism of C. pipiens complex mosquitoes to organophosphate (OP) insecticides. This process is achieved mainly by gene amplification or occasionally by gene up regulation $[6,7]$. Some studies indicated that gene duplication or amplification may be a more common adaptive evolutionary mechanism in arthropods, and that certain genomic loci may be "hot spots" for gene duplication, as evidenced by parallel evolution in several arthropod species [8]. 
In the C. pipiens complex, two carboxylesterase loci, Est-3 (encoding esterase A) and Est-2 (encoding esterase B), are amplified in the genome and subsequently confer resistance to insecticides $[9,10]$. Est-3 and Est-2 are usually in complete linkage disequilibrium when amplified and are thus referred to as the Ester superloci [11]. To date, 13 alleles that confer insecticide resistance have been identified at the Ester superloci in the $C$. pipiens complex. These alleles (with the corresponding overproduced esterases indicated in parentheses) are Ester ${ }^{A 1}$ (A1), Ester ${ }^{2}$ (A2-B2), Ester ${ }^{4}$ (A4-B4), Ester ${ }^{5}$ (A5-B5), Ester $^{8}$ (A8-B8), Ester ${ }^{9}$ (A9-B9), Ester ${ }^{B 1}$ (B1), Ester ${ }^{B 6}$ (B6), Ester $^{B 7}$ (B7), Ester ${ }^{B 10}$ (B10), Ester ${ }^{11}$ (A11-B11), Ester ${ }^{B 12}$ (B12), and Ester ${ }^{A 13}$ (A13) [2,7,12-15]. Some resistant alleles are distributed globally. For instance, Ester ${ }^{2}$ is found in Africa, Asia, Europe, North America, and the Caribbean [12,16]. Meanwhile, some resistant alleles are found in restricted geographic areas. For example, Ester ${ }^{8}$, Ester $^{9}$, Ester ${ }^{B 10}$, and Ester ${ }^{11}$ are endemic to China [14,17-19]. Thus, an unusual diversity of Ester alleles is observed in field populations in China, where Ester ${ }^{B 1}$, Ester $^{2}$, Ester ${ }^{8}$, Ester ${ }^{9}$, Ester ${ }^{B 10}$, and Ester ${ }^{11}$ have been reported to coexist in one population $[13,14]$. The polymorphism of resistant esterase alleles may be the result of changes in insecticide use and/or of a recent contact between relatively isolated treated areas through migration [13].

The identification and monitoring of the frequencies of these resistant Ester alleles in field populations of mosquitoes are vital not only to the control of vector mosquitoes and the diseases they transmit, but also to field evolutionary studies of these alleles. Current methods of genotyping or allele identification include restriction fragment length polymorphism (RFLP) identification, random amplified polymorphic detection (RAPD), amplified fragment length polymorphism detection (AFLPD), polymerase chain reaction (PCR), DNA sequencing, allele specific oligonucleotide (ASO) probes, and hybridization to DNA microarrays or beads. The most applied method in studies of Culex Ester alleles is the starch gel electrophoresis, which only reveals the phenotype of Ester alleles instead of the genotype. In this paper, we designed specific primers and selected the appropriate restriction endonucleases for use in PCR-RFLP to differentiate between resistant and nonresistant Ester alleles in C. pipiens complex mosquitoes. The effectiveness of the PCRRFLP system was verified in field-collected mosquitoes.

\section{Methods}

\section{Mosquitoes}

Eight standard $C$. pipiens complex strains were used. These strains are S-LAB, which is an OP-susceptible C. $p$. quinquefasciatus strain without increased esterase activity [20]; BJSU, an insecticide-susceptible C. p. pallens strain collected from Beijing in the 1970s and laboratory-reared for over 40 years without insecticide exposure; and SB1, SA2, MAO2, LING, KARA2, and WU, which are homozygous C. p. quinquefasciatus for Ester $^{B 1}$, Ester ${ }^{2}$, Ester $^{8}$, Ester $^{9}$, Ester $^{B 10}$, and Ester ${ }^{11}$, respectively $[13,18,21]$. Two field populations were also obtained: R-SG, which was C. p. quinquefasciatus and collected from Foshan in Guangdong Province (South China) in July 2007, and TAA, which was C. p. pallens and collected from Tai'an in Shandong Province (North China) in July 2010 [22].

\section{DNA isolation and PCR-RFLP}

Genomic DNA from intact single adult mosquitoes or from their head-thoraces was extracted using the cetyl trimethyl ammonium bromide (CTAB) method, as described by Roger and Bendich [23]. Based on the GenBank Ester allele sequences (Tables 1 and 2), the Ester $B$ allele fragments were amplified using the Bdir (5'AGC T TAACCGT TCAGACCAA3') and Brev (5'CAGT CCAACGTTTCGGTCCA3') primers, whereas the EsterA alleles were amplified using the Adir (5'CTTTATGAGAG GATCTAGTGG3') and Arev (5'CAAGCTTCACGACAC

Table 1 PCR and RFLP products of esterase B alleles

\begin{tabular}{|c|c|c|c|c|c|}
\hline \multirow[t]{2}{*}{ Alleles } & \multirow[t]{2}{*}{ GenBank ID } & \multirow[t]{2}{*}{ PCR (bp) } & \multicolumn{2}{|l|}{ Dral digestion (bp) } & \multirow[t]{2}{*}{ Xbal digestion (bp) } \\
\hline & & & Predicted & In gel & \\
\hline B1 & M32328 & 945 & $512,369,64$ & 512,369 & 945 \\
\hline B2 & Z86069 & 941 & 677,244 & 677,244 & 941 \\
\hline B8 & EF174325 & 2443 & $951,888,424,89,69,22$ & $951,424,180$ & 2443 \\
\hline B9 & JQ866911 & 936 & $402,292,242$ & $402,292,242$ & 936 \\
\hline B11 & EF174328 & 942,1165 & $519,423,742,423$ & $742,519,423$ & 942,1165 \\
\hline B10 & EF174326 & 2442 & $951,888,424,89,68,22$ & $951,424,180$ & 2442 \\
\hline$S p-B^{1}$ & JQ812615 & 942 & $519,375,48$ & 519,375 & 353,589 \\
\hline$S q-B^{2}$ & JQ341053 & 936 & $402,292,242$ & $402,292,242$ & 936 \\
\hline
\end{tabular}

${ }^{1}$ Susceptible Ester B allele of C. p. pallens.

${ }^{2}$ Susceptible Ester $B$ allele of $C$. p. quinquefasciatus. 
Table 2 PCR and RFLP products of esterase A alleles

\begin{tabular}{llll}
\hline Alleles & GenBank ID & PCR (bp) & ApaLI digestion (bp) \\
\hline B1-A & JQ780068 & 714 & 321,393 \\
\hline A2 & Z86069 & 713 & 321,392 \\
\hline A8 & AJ302089 & 713 & $98,223,392$ \\
\hline A9 & AJ302090 & 713 & 98,615 \\
\hline A11 & EF174327 & 713 & $98,223,409$ \\
\hline B10-A & AJ302090 & 713 & 98,615 \\
\hline Sp-A & JQ812614 & 713 & 321,392 \\
\hline Sq-A & JQ812613 & 713 & 321,392 \\
\hline
\end{tabular}

${ }^{1}$ Susceptible Ester $A$ allele of C. p. pallens.

${ }^{2}$ Susceptible Ester $A$ allele of $C$. $p$. quinquefasciatus.

ATCTC3') primers. The $50 \mu \mathrm{l}$ PCR mixture contained $1 \mu \mathrm{l}$ of genomic DNA (50 ng/ $\mu \mathrm{l}$ to $100 \mathrm{ng} / \mu \mathrm{l}$ ), $0.25 \mu \mathrm{M}$ of each primer, $0.2 \mathrm{mM}$ of each $\mathrm{dNTP}$, and 2.5 units of LA Taq polymerase (Takara, Otsu, Shiga, Japan) in a $1 \times$ reaction buffer. PCR was performed on a thermocycler (Mastercycler Gradient, Eppendorf, Hamburg, Germany) at a denaturing step of $94^{\circ} \mathrm{C}$ for $4 \mathrm{~min}$, followed by 35 cycles of $94^{\circ} \mathrm{C}$ for $45 \mathrm{~s}, 58^{\circ} \mathrm{C}$ for $45 \mathrm{~s}$, and $72^{\circ} \mathrm{C}$ for $2 \mathrm{~min}$ and $40 \mathrm{~s}$ for the Ester $B$ gene or $1 \mathrm{~min}$ and $10 \mathrm{~s}$ for the EsterA gene. A final extension of $10 \mathrm{~min}$ at $72^{\circ} \mathrm{C}$ followed. After verification via $1 \%$ agarose gel electrophoresis, the PCR products were digested with the restriction enzymes DraI or XbaI for EsterB and ApaLI for Ester $A$ at $37^{\circ} \mathrm{C}$ for $2 \mathrm{~h}$ in accordance with the manufacturer's instructions (BioLabs, Ipswich, MA, USA). The digested products were electrophoresed in $2 \%$ agarose gel and photographed under ultraviolet light illumination using a gel imaging system (Gene Company, Hong Kong, China).

\section{Starch gel electrophoresis}

Single adult mosquitoes from the R-SG and TAA field populations were cut into two parts: the head-thorax and the abdomen. The abdomen of each mosquito was homogenized in $10 \mu \mathrm{l}$ distilled water using a pestle. The homogenate was spread onto a Whatman Grade No. 3 filter paper $(3 \mathrm{~mm} \times 8 \mathrm{~mm})$ and analyzed via starch gel electrophoresis to identify the carboxylesterase phenotypes [24]. The head-thorax was used in PCR-RFLP for carboxylesterase genotype identification. At least 10 individuals from each population were analyzed.

\section{Results and discussion}

Discrimination of carboxylesterase alleles in standard strains via PCR-RFLP

To discriminate the carboxylesterase alleles, the Ester $B$ allele fragments were first amplified by PCR. Most PCR products of the Ester $B$ alleles were approximately 900 bp long, whereas those of Ester B8 and Ester B10 were approximately $2400 \mathrm{bp}$ in length (Figure. 1a and

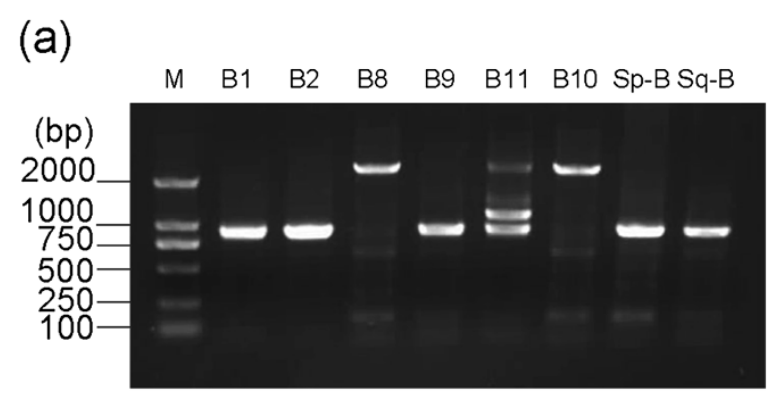

(b)

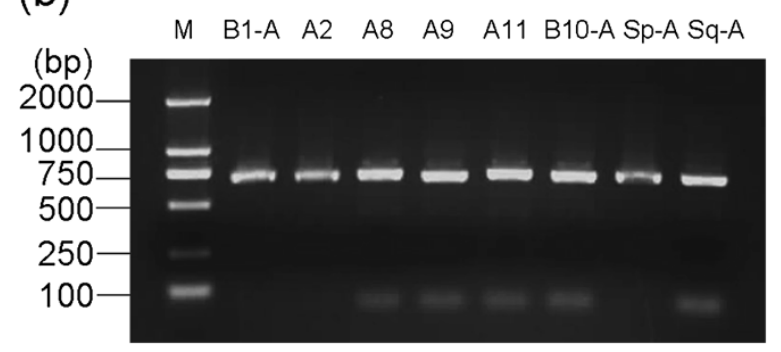

Figure 1 Agarose gel electrophoresis for PCR products of (a) esterase $B$ and (b) esterase $A$ from standard Culex pipiens complex strains. M, Marker D2000; B1 from the SB1 strain; A2-B2 from the SA2 strain; $A 8-B 8$ from the MAO2 strain; $A 9-B 9$ from the LING strain; A11-B11 from the WU strain; B10 from the KARA2 strain; Sp, susceptible esterases of C. p. pallens from the BJSU strain; Sq, susceptible esterases of C. p. quinquefasciatus from the S-LAB strain.

Table 1). Meanwhile, the PCR product of Ester B11 showed two predominant bands that correspond to 942 and $1165 \mathrm{bp}$ fragments. Sequencing data show that the 942 bp band is Ester B11, whereas the 1165 bp band had a 223 bp insertion in one Ester B11 intron. This insertion may have originated from gene recombination or transposition in the genome. Whether this insertion affects the insecticide resistance in mosquitoes remains to be determined.

After the PCR products were digested by the restriction enzyme DraI, the Ester B alleles showed various digestion patterns. Given the resolution limit of the $2 \%$ agarose gel electrophoresis, some Ester $B$ allele digestion patterns in the agarose gel electrophoresis differed from the predicted theoretical patterns (Table 1). In the electrophoresis graph (Figure. 2a), the Ester B2 (lane 2) and Ester $B 11$ (lane 5) patterns were unique, thereby allowing the differentiation of Ester ${ }^{2}$ and Ester ${ }^{11}$ from the other alleles. The 223 bp insertion in the 1165 bp Ester B11 PCR product resulted in the appearance of a 742 bp excess band during digestion. Based on DraI digestion, three pairs of Ester $B$ alleles were distinguished by differences in their migration patterns (Figure. 2a): Ester B1 (lane 1) and the susceptible C. p. pallens Ester B (lane 7); Ester B8 (lane 3) and Ester B10 (lane 6); Ester B9 (lane 4) and the susceptible C. p. quinquefasciatus Ester B (lane 8). 


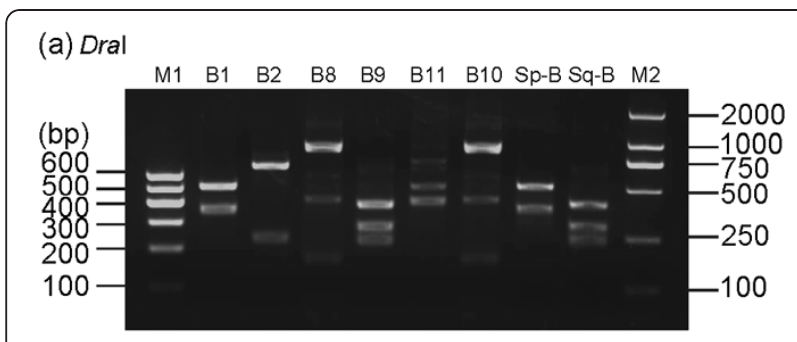

(b) $X$ bal

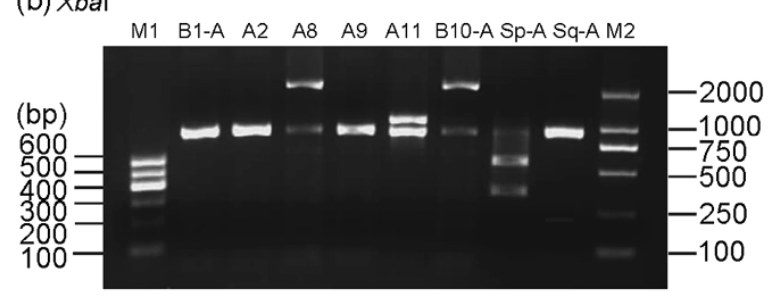

(c) ApaLI

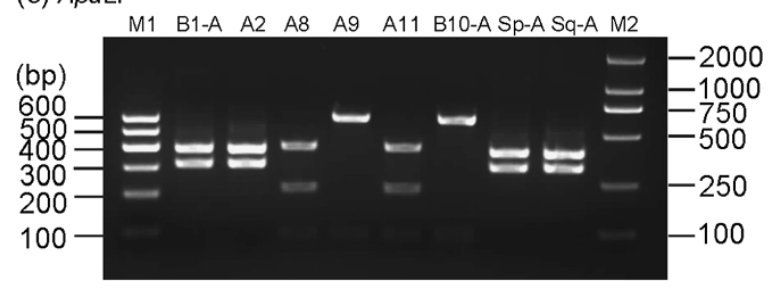

Figure 2 (a) Dral and (b) Xbal PCR-RFLP profiles of esterase B and (c) ApaLI PCR-RFLP profiles of esterase A from standard C. pipiens complex strains. M1, Marker I. M2, Marker D2000. The standard strains are the same as those described in Figure 1.

The PCR products of the three pairs of Ester $B$ alleles were digested by the restriction enzyme XbaI (Figure. 2b) to allow differentiation among members of the same pair. The pair consisting of Ester B1 (lane 1) and the susceptible $C$. $p$. pallens Ester $B$ (lane 7) displayed different digestion profiles, which allowed the differentiation of Ester $^{B 1}$ from the susceptible C. p. pallens. However, the $X b a I$ enzyme could not discriminate Ester B8 (lane 3) from Ester B10 (lane 6), or Ester B9 (lane 4) from the susceptible C. p. quinquefasciatus Ester $B$ (lane 8). At this step, four Ester alleles had already been distinguished from one another: Ester ${ }^{2}$, Ester $^{11}$, Ester $^{B 1}$, and the susceptible C. p. pallens.

Ester $^{8}$ and Ester ${ }^{9}$ were differentiated from Ester ${ }^{B 10}$ and the susceptible C. $p$. quinquefasciatus, respectively, by amplifying an approximately $700 \mathrm{bp}$ fragment of their Ester $A$ via PCR using specific primers (Figure. $1 \mathrm{~b}$ and Table 2) and then digesting the fragment with the restriction enzyme ApaLI. Ester A8 (lane 3) displayed digestion profiles that differ from that of the Ester ${ }^{B 10}$ Ester $A$ (lane 6) (Figure. 2c). In addition, Ester A9 (lane 4) displayed profiles that differ from those of the susceptible C. p. quinquefasciatus Ester A (lane 8) (Figure. 2c). Thus, the six resistant Ester alleles Ester ${ }^{B 1}$, Ester $^{2}$, Ester $^{8}$, Ester $^{9}$,
Ester $^{B 10}$, and Ester ${ }^{11}$, as well as the susceptible alleles, were correctly identified (Figure. 3).

Ester $^{A 1}$, Ester ${ }^{4}$,Ester ${ }^{5}$, Ester $^{B 6}$, Ester ${ }^{B 7}$, Ester $^{B 12}$, and Ester $^{A 13}$ are found in other places in the world. However, given that no sequence information on the association of Ester $^{B 6}$, Ester $^{B 7}$, and Ester $B$ to Ester ${ }^{A 1}$ and Ester ${ }^{A 13}$ is available, and that only a partial sequence of Ester ${ }^{B 12}$ is currently known, the designed PCR-RFLP cannot be used to differentiate these alleles. The predicted PCR product sizes for Ester B4 and Ester B5 are 1289 and 1337 bp according to the Ester ${ }^{4}$ and Ester ${ }^{5}$ sequences, respectively; these values deviate from those of other Ester $B$ alleles (Table 1). However, the DraI digestion profiles of Ester B4 and Ester B5 (764 and 467 bp for Ester B4, and 770 and 518 bp for Ester ${ }^{5}$ ) may be difficult to distinguish in $2 \%$ agarose gel electrophoresis. No $X b a \mathrm{I}$ cut site exists in Ester B4 and Ester B5. The predicted PCR products of Ester A4 and Ester A5 are 714 and 713 bp, respectively. Only Ester A5 can be cut by ApaLI to produce 321 and 392 bp bands. Thus, the designed PCR-RFLP can identify eight resistant Ester alleles $\left(\right.$ Ester $^{B 1}$, Ester $^{2}$, Ester $^{4}$, Ester $^{5}$, Ester $^{8}$, Ester $^{9}$, Ester $^{B 10}$, and Ester $^{11}$ ) and two susceptible alleles.

\section{Identification of carboxylesterase alleles in mosquitoes from field populations}

The phenotype and genotype of carboxylesterase alleles in mosquitoes from two field populations, R-SG (C. $p$. quinquefasciatus) and TAA (C. p. pallens), were identified through starch gel electrophoresis and PCRRFLP. Of the eight mosquitoes from the R-SG population, Nos. 4, 5, 7, and 9 showed the A8-B8 phenotype in starch gel electrophoresis (Figure. 4a). PCR-RFLP results confirm that these mosquitoes were homozygous with

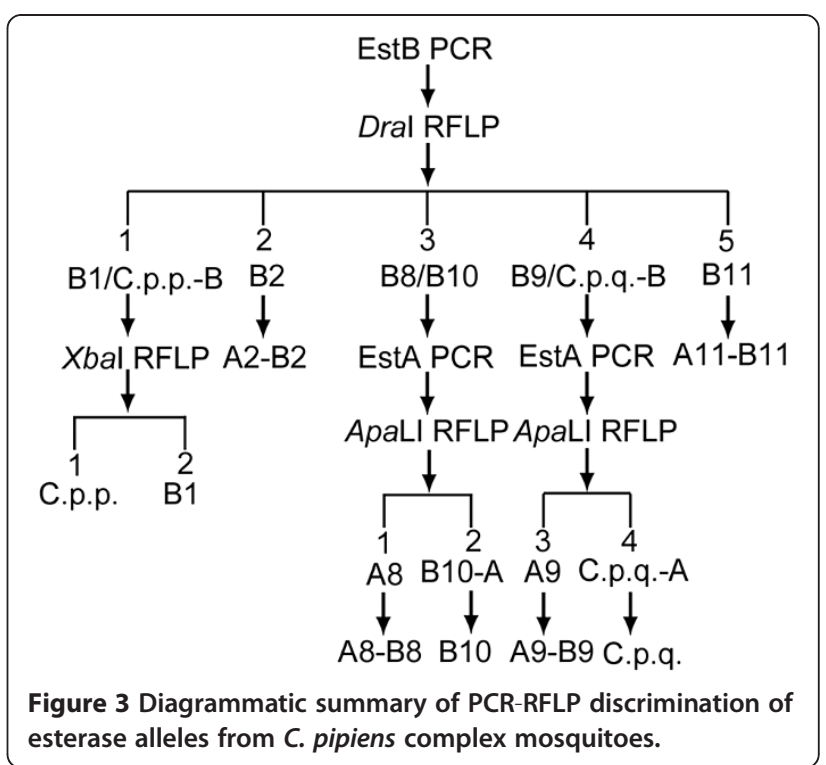




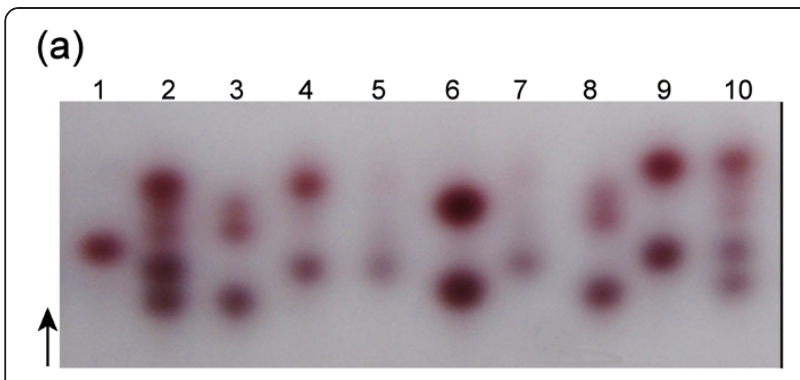

(b)

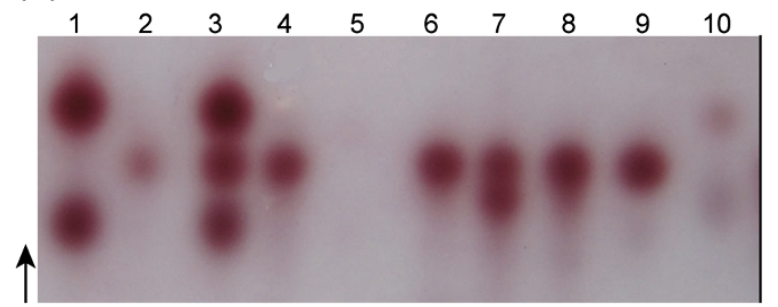

Figure 4 High-activity esterases of single adults from the R-SG and TAA field-collected populations, as determined via starch gel electrophoresis. (a) R-SG population: 1, B1 from the SB1 strain as control; 2-5 and 7-10, R-SG field samples; 6, A2-B2 from the SA2 strain as control. (b) TAA population: 1, A2-B2 from the SA2 strain as the control; 2-9, TAA field samples; 10, A11-B11 from the WU strain as control.

Ester $^{8}$ (Figure 5 and Figure 6). Starch gel electrophoresis results suggest that the Nos. 3 and 8 mosquitoes are heterozygous to A2-B2 and A9-B9 or A9-B10 and A9-B9 because of the similar mobilities of A2-B2 and A9-B10 [14]. However, PCR-RFLP results indicate that these mosquitoes are actually heterozygous to A9-B10 and B2 (Figure 5

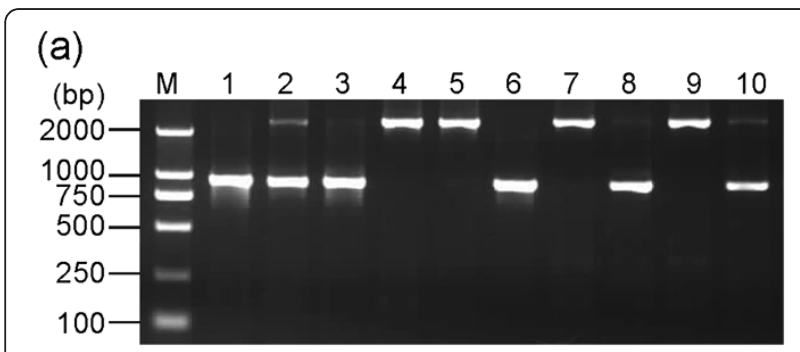

(b)

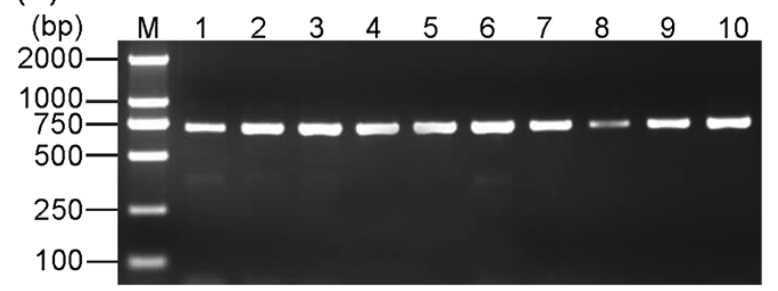

Figure 5 Agarose gel electrophoresis of the PCR products of (a) esterase $B$ and (b) esterase $A$ from the R-SG population. $M$,

Marker D2000; 1, B1 from the SB1 strain as control; 6, A2-B2 from the SA2 strain as control; 2-5 and 7-10, R-SG field samples.

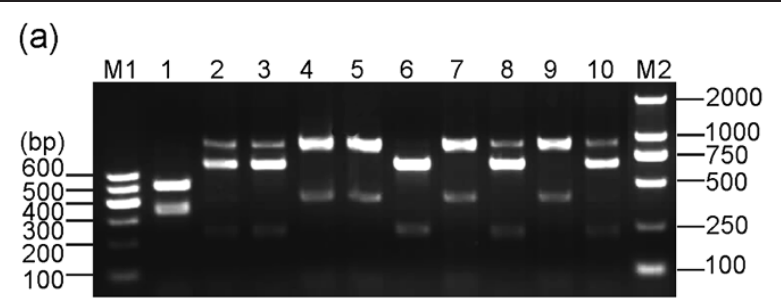

(b)

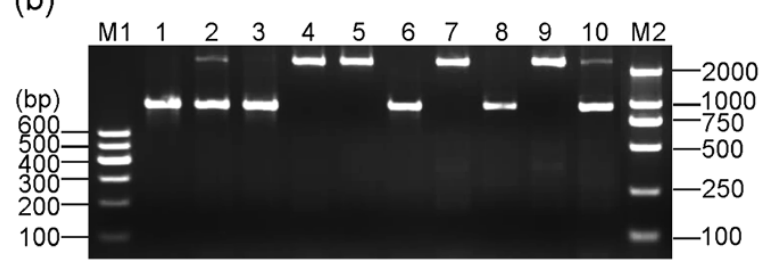

(c)

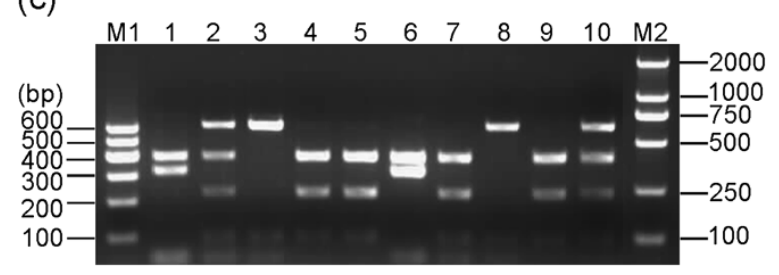

Figure 6 (a) Dral and (b) Xbal PCR-RFLP profiles of esterase B and (c) ApaLI PCR-RFLP profiles of esterase A from the R-SG population. M1, Marker I; M2, Marker D2000; 1-10, as described in Figure 5.

and Figure 6). Three esterase Bs and two esterase As were found in the starch gel electrophoresis profile of Nos. 2 and 10 mosquitoes (Figure. 4a). The whole set of PCR-RFLP shows that the No. 2 mosquito expressed A8B8, A9-B9, and B2, whereas the No. 10 mosquito expressed A8-B8, A9-B10, and B2 (Figure 5 and Figure 6). The fewer than expected DraI digestion bands of esterase $\mathrm{B}$ alleles in mosquito No. 2 (Figure 6A, lane 2) could be due to the higher gene copy number of $\mathrm{B} 2$ in the genome over B8 and B9. Without the PCR-RFLP results, the differentiation of the phenotypes of the two mosquito types would have been difficult.

Most of the eight mosquito types from the TAA population (Figure. 4b) overproduced esterase B1 (No. 2, 4, 6, 7,8 , and 9 mosquitoes). The No. 3 mosquito was heterozygous to B1 and A2-B2. These phenotypes were confirmed by PCR-RFLP (Figure 7 and Figure 8). The No. 5 individual did not appear to have overproduced esterases based on the light-colored band in the starch gel electrophoresis. However, PCR-RFLP results indicate the presence of A2-B2 and A9 (Figure 7 and Figure 8). The results for the two field populations show that the A2B2 and A9-B9 linkages are not always established. This result deviates from the usual observations and theories [7]. By now the recombination event leading to the existence of three esterase $B$ alleles in one individual 


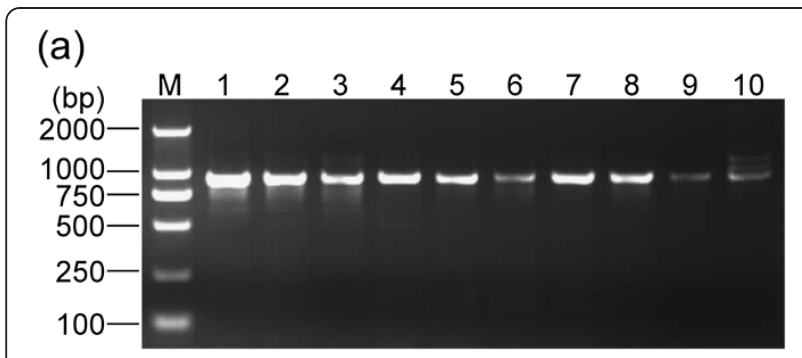

(b)

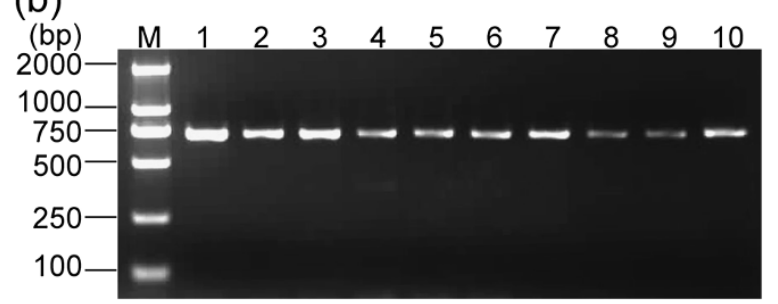

Figure 7 Agarose gel electrophoresis of the PCR products of (a) esterase $B$ and (b) esterase $A$ from the TAA population. $M$,

Marker D2000; 1, A2-B2 from the SA2 strain as control; 2-9, TAA field samples; 10, A11-B11 from the WU strain as control.

mosquito has only been observed in field populations of China [13 and this study]. The dislinkage between A2 and $\mathrm{B} 2$ or $\mathrm{A} 9$ and $\mathrm{B} 9$ probably results from the rare recombination event among these esterase alleles.

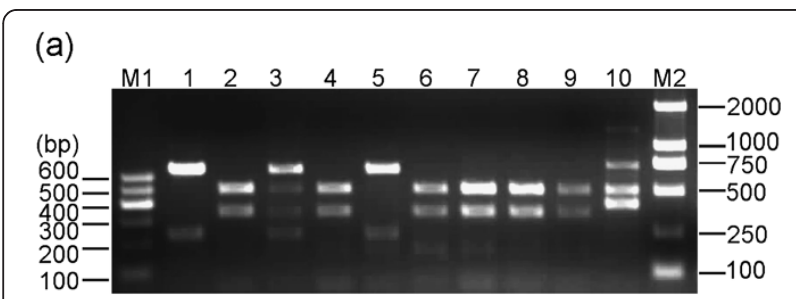

(b)

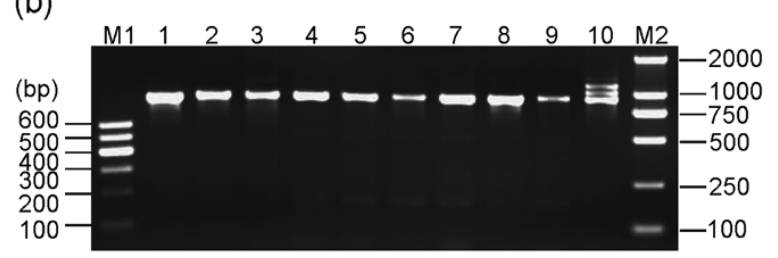

(c)

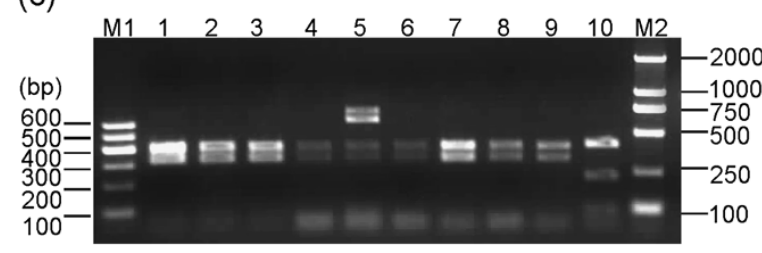

Figure 8 (a) Dral and (b) Xbal PCR-RFLP profiles of esterase B and (c) ApaLI PCR-RFLP profiles of esterase A from the TAA population. M1, Marker I; M2, Marker D2000; 1-10, as described in Figure 7.

\section{Conclusions}

The custom-designed PCR-RFLP method can be used to differentiate the insecticide-resistant esterase alleles existing in China. The method can help monitor the evolutionary dynamics of these esterase alleles and identify new esterase alleles in field populations of C. pipiens complex.

\section{Competing interests}

The authors declare that they have no competing interests.

\section{Authors' contributions}

$\mathrm{HZ}$ performed the study, analyzed the data and drafted the manuscript. FM supplied the BJSU strain and helped draft the manuscript. CQ supervised the study and helped draft the manuscript. FC conceived, designed the study, and finalized the manuscript. All authors read and approved the final version of the manuscript.

\section{Acknowledgments}

This work was supported by grants from the Major State Basic Research Development Program of China (973 Program) (No. 2012CB114102) and the Chinese Academy of Sciences (No. KSCX2-EW-N-5).

\section{Author details}

${ }^{1}$ State Key Laboratory of Integrated Management of Pest Insects and Rodents, Institute of Zoology, Chinese Academy of Sciences, Beijing 100101, China. ${ }^{2}$ Department of Vector Biology and Control, National Institute for Communicable Disease Control and Prevention, China CDC, Beijing 102206, China.

Received: 8 August 2012 Accepted: 13 September 2012 Published: 24 September 2012

\section{References}

1. Cui F, Raymond M, Qiao CL: Insecticide resistance in vector mosquitoes in China. Pest Manag Sci 2006, 62:1013-1022.

2. Ben Cheikh R, Berticat C, Berthomieu A, Pasteur N, Ben Cheikh H, Weill M: Characterization of a Novel High-Activity Esterase in Tunisian Populations of the Mosquito Culex pipiens. J Econ Entomol 2008, 101:484-491.

3. Zhao TY, Lu BL: Biosystematics of Culex pipiens complex in China. Insect Sci 1995, 2:1-8.

4. Yan SG, Wu ZH, Cui F, Zhao Q, Qiao CL: Dynamics of esterase alleles in Culex pipiens complex mosquitoes in Beijing. J Econ Entomol 2008, 101:1897-1902.

5. Oppenoorth FJ: Biochemistry and genetics of insecticide resistance. In Comprehensive Insect Physiology, Biochemistry and Pharmacology. Edited by Kerkut GA, Gilbert LI. New York: Pergamon; 1985:731-773. Insect Control, vol.12.

6. Rooker S, Guillemaud T, Berge' J, Pasteur N, Raymond M: Coamplification of esterase $A$ and $B$ genes as a single unit in Culex pipiens mosquitoes. Heredity 1996, 77:555-561.

7. Raymond M, Chevillon C, Guillemaud T, Lenormand T, Pasteur N: An overview of the evolution of overproduced esterases in the mosquito Culex pipiens. Phil Trans R Soc Lond B Biol Sci 1998, 353:1707-1711.

8. Bass C, Field LM: Gene amplification and insecticide resistance. Pest Manag Sci 2011, 67:886-890.

9. Guillemaud T, Makate N, Raymond N, Hirst B, Callaghan A: Esterase gene amplification in Culex pipiens. Insect Mol Biol 1997, 64:319-327.

10. Guillemaud T, Lenormand T, Bourguet D, Chevillon C, Pasteur N, Raymond M: Evolution of resistance in Culex pipiens: allele replacement and changing environment. Evolution 1998, 52:443-453.

11. Lenormand T, Guillemaud T, Bourguet D, Raymond M: Evaluating gene flow using selected markers: a case study. Genetics 1998, 149:1383-1392.

12. Raymond M, Berticat C, Weill M, Pasteur N, Chevillon C: Insecticide resistance in the mosquito Culex pipiens: what have we learned about adaptation? Genetica 2001, 112-113:287-296. 
13. Cui $F$, Lin $L Y$, Qiao $C L$, Xu Y, Marquine $M$, Weill M, Raymond $M$ : Insecticide resistance in Chinese populations of the Culex pipiens complex through esterase overproduction. Entomol Exp Appl 2006, 120:211-220.

14. Cui F, Weill M, Berthomieu A, Raymond M, Qiao CL: Characterization of novel esterases in insecticide-resistant mosquitoes. Insect Biochem Molec Biol 2007, 37:1131-1137.

15. Ben Cheikh R, Berticat C, Berthomieu A, Pasteur N, Ben Cheikh H, Weill M: Genes conferring resistance to organophosphorus insecticides in Culex pipiens (Diptera: Culicidae) from Tunisia. J Med Entomol 2009, 46:523-530.

16. Raymond M, Callaghan A, Fort P, Pasteur N: Worldwide migration of amplified insecticide resistance genes in mosquitoes. Nature 1991 350:151-153.

17. Qiao CL, Marquine M, Pasteur N, Raymond M: A new esterase gene amplification involved in OP resistance in Culex pipiens mosquitoes from China. Biochem Genet 1998, 36:417-425.

18. Weill M, Marquine M, Berthomieu A, Dubois MP, Bernard C, Qiao CL, Raymond M: Identification and characterization of novel organophosphate detoxifying esterase alleles in the Guangzhou area of China. J Am Mosa Control Assoc 2001, 17:238-244.

19. Cui F, Tan Y, Qiao CL: Filariasis vector in China: insecticide resistance and population structure of mosquito Culex pipiens complex. Pest Manag Sci 2007, 63:453-458.

20. Georghiou GP, Metcalf RL, Gidden FE: Carbamate-resistance in mosquitoes: selection of Culex pipiens fatigans Wiedmann $(=C$. quinquefasciatus Say) for resistance to Baygon. Bull World Health Organ 1966, 35:691-708.

21. Berticat C, Rousset F, Raymond M, Berthomieu A, Weill M: High Wolbachia density in insecticide-resistant mosquitoes. Proc Biol Sci 2002, 269:1413-1416.

22. Liu YY, Zhang HY, Qiao CL, Lu XP, Cui F: Correlation between carboxylesterase alleles and insecticide resistance in Culex pipiens complex from China. Parasit Vectors 2011, 4:236-242.

23. Roger SO, Bendich AJ: Extraction of DNA from plant tissues. In Plant Molecular Biology Manual. Edited by Gelvin SB, Schilperoort RA. Boston: Kluwer Academic Publishers; 1988:1-10.

24. Pasteur NP, Bonhomme G, Catalan F, Britton-Davidian J: Practical isozyme genetics. Chichester: Ellis Horwood Ltd; 1988:215.

doi:10.1186/1756-3305-5-209

Cite this article as: Zhang et al:: Identification of resistant carboxylesterase alleles in Culex pipiens complex via PCR-RFLP. Parasites \& Vectors 2012 5:209.

\section{Submit your next manuscript to BioMed Central and take full advantage of:}

- Convenient online submission

- Thorough peer review

- No space constraints or color figure charges

- Immediate publication on acceptance

- Inclusion in PubMed, CAS, Scopus and Google Scholar

- Research which is freely available for redistribution 